\title{
Description and impact of a distance mathematics course for grade 10 to 12 teachers
}

\author{
Gerrit Stols $^{a}$, Alwyn Olivier ${ }^{b}$ and Diane Grayson ${ }^{c}$ \\ ${ }^{\mathrm{a}, \mathrm{c}}$ University of Pretoria and ${ }^{\mathrm{b}}$ University of Stellenbosch \\ Email: ${ }^{a}$ gerrit.stols@up.ac.za, ${ }^{b}$ aio@sun.ac.za and ${ }^{c}$ dgrayson@absamail.co.za
}

This paper explores the impact of a one-year in-service distance education mathematics course that follows a problem-solving approach. The course aims to develop teachers' mathematical thinking skills. Results show that the course improved the teachers' confidence, problem-solving skills and teaching skills. Results also show that the course on mathematical thinking skills helps to improve teachers' understanding of mathematics content.

\section{Introduction and background}

The fact that there is a crisis in mathematics education is common knowledge and a cause for concern. For the past five years only approximately 20,000 grade 12 learners (4\%) a year have passed mathematics on Higher Grade (HG) in the Senior Certificate examinations (Department of Education, 2001; Kahn, 2004). Given that a pass in HG mathematics is a prerequisite for entry into science-based studies at university, there are serious implications for the country's ability to produce enough scientifically skilled professionals. It was with these points in mind that a distancebased course for grade 10-12 teachers was developed by the Centre for the Improvement of Mathematics, Science and Technology Education (CIMSTE) at the University of South Africa (UNISA). The course was designed and written by the second author in 2001 and 2002 and implemented by the first author for the first time in 2002. The focus of the course is on problemsolving, in the context of algebra.

In the planning phase of a course, an important question is what the course should look like in order to have the maximum impact possible on teachers and their learners. What kind of mathematical skills and knowledge do teachers need in order to teach effectively? It is impossible to answer such questions before we have decided what we want from the learners. We naturally want the learners to be able to do mathematics, but then the question arises: What is mathematics and how do you learn it? It is therefore important, when designing a course, to start with a view of the nature of mathematics and the learning of mathematics. Dossey, McCrone, Giordano and Weir (2002) believe that there is no general agreement on the question:
The wide variety of its [mathematics'] applications in our society is easy to list. But, the nature of mathematics itself is hard to capture. This results from a lack of consensus, even among mathematicians, as to what constitutes 'mathematics' and what 'doing mathematics' means. (2002: 4)

In reality, most professional mathematicians spend little thought on the fundamental nature of their subject. What we want to know is: which skills do we value as mathematical skills? This can change according to changes in our society. Confrey and Lachance explain why:

These skills (computational skills) allowed students to secure jobs and to become informed citizens in an industrial society. However, with advances in technology, such computational skills are no longer as important. Instead, students need to develop critical-thinking skills to interpret data appropriately and to use technology to solve more complex problems. Thus, changes in our society have led to a change in what we value in mathematical skills. (2000: 232)

We currently support the following view expressed in the South African National Curriculum Statement on grade 10-12 mathematics (Department of Education, 2003):

Mathematics enables creative and logical reasoning about problems in the physical and social world and in the context of mathematics itself. It is a distinctly human activity practised by all cultures. Knowledge in the mathematical sciences is constructed through the establishment of descriptive, numerical and symbolic relationships. Mathematics is based on 
observing patterns which with rigorous logical thinking, leads to theories of abstract relations. Mathematical problemsolving enables us to understand the world and make use of that understanding in our daily lives. Mathematics is developed and contested over time by social interaction through both language and symbols. (2003:7)

In terms of this statement, we want the learners to:

- Solve problems, using creative and logical reasoning.

- Find relationships and express them symbolically.

- Observe patterns to find relationships and prove them.

To expand on this, in the words of the Education Development Centre (2000), "Students need to be thinkers: pattern hunters, experimenters, describers, tinkerers, inventors, visualisers, conjecturers, guessers and seekers of reasoned argument and proof." We can describe justifying, explaining, analysing, generalising and defining as mathematical thinking. We believe the best way to help learners to develop the ways of thinking that are characteristic of mathematics is through problem-solving (Education Development Centre, 2000: xiv). According to Resnick (1989), theory and research show that we develop habits and skills of interpretation and meaning construction though a process of socialisation or enculturation rather than through instruction:

...becoming a good mathematical problem-solver - becoming a good thinker in any domain - may be as much a matter of acquiring the habits and dispositions of interpretation and sense-making as of acquiring any particular set of skills, strategies, or knowledge. If this is so, we may do well to conceive of mathematics education less as an instructional process (in the traditional sense of teaching specific, well-defined skills or items of knowledge), than as a socialisation process. In this conception, people develop points of view and behaviour patterns associated with gender roles, ethnic and familial cultures, and other socially defined traits. When we describe the processes by which children are socialised into these patterns of thought, affect, and action, we describe long-term patterns of interaction and engagement in a social environment. (1989: 58)
This view of enculturation highlights the importance of perspective and point of view as core aspects of knowledge. The case can be made that a fundamental component of thinking mathematically is having a mathematical point of view, or having a mathematical attitude of mind - seeing the world in the way mathematicians do.

The focus of our course is therefore on developing a mathematical attitude of mind and the way to do it is to immerse participants in a typical mathematical culture.

\section{Theoretical context}

One of the most important factors influencing learner performance is the teacher. In a synthesis of research related to the President's Education Initiative, Taylor and Vinjevold (1999) indicate that there are problems with teachers' knowledge and skills and, in consequence, with their teaching approaches:

... reform initiatives aimed at revitalising teacher education and classroom practices must not only create a new ideological orientation consonant with the goals of the new South Africa. They also need to get to grips with what is likely to be a far more intractable problem: the massive upgrading and scaffolding of teachers' conceptual knowledge and skills.

...the fundamental mechanism for its propagation [the vicious cycle of rote learning] is the lack of conceptual knowledge, reading skills and spirit of enquiry amongst teachers. (1999: 160)

What is needed if mathematics teachers are to become more effective are professional development opportunities to strengthen their conceptual knowledge and problem-solving skills. It comes as no surprise that a focus of the new South African Further Education and Training (FET) curriculum is on helping learners develop problem-solving skills because problem-solving is central to the constructivist-based teaching of mathematics. A problem-centred learning approach is based on the acceptance that learners construct their own mathematical knowledge. The difficulty that arises, however, is that the teachers are not trained to teach problem-solving and did not experience the power of a problem-centred teaching approach themselves. The way in which teachers have been taught themselves plays an important role in the way they think about teaching. It is therefore important in a course for the training of teachers to 
allow those teachers to experience problem-solving first hand. In a report, the National Commission on Teaching and America's Future (1996:20) discuss the fact that teacher preparation and professional development programmes must consciously examine the expectations embodied in new curriculum frame-works. The report also comments on the need for these programmes to develop strategies that help teachers learn to teach in these much more demanding ways. Teachers' programmes, according to Loucks-Horsely, Hewson, Love, and Stiles (1998: 36), must be organised around problem-solving and must be directly related to teachers' work with their students.

This paper discusses the impact of a problemsolving course on a group of 27 teachers, in terms of both their mathematical understanding and their attitudes towards mathematics and the teaching of mathematics.

\section{Description of the course}

The purpose of the UNISA (University of South Africa) Mathematics for Teachers course, for which the students receive 12 credits (an average teacher will take about 120 hours to complete the course successfully), was to improve the teachers' mathematical thinking skills and pedagogical content knowledge, mainly in the context of problems. The duration of the course is one year and is offered by means of distance teaching. UNISA is a distance education institution, a factor which poses challenges in itself. To try to overcome some of the problems presented by a distance course (e.g. sharing solutions through discussions with others), we held three workshops of two hours each. We encouraged the teachers to form peer groups by explaining the advantages of such groups to them and sending them a list of the telephone numbers and addresses of all the students enrolled for the course.

The central focus of the course is on problemsolving, that is, non-routine problem-solving either through illustrations of the process of problem-solving, or through students' own engagement with problems. In order to encourage the teachers to reflect regularly on the mathematics that they had learnt and to think of ways to introduce their new-found knowledge in the classroom, we asked them to keep and submit a journal and encouraged them to update their journals regularly - at least once a week. As part of the course, teachers were required to complete four assignments, which we marked and returned to them.

\section{Examples of problems from the study guide}

The examples below are taken from the course study guide. They will give the reader a better idea of what we mean when we ask learners to find relationships and express them symbolically and observe patterns to find relationships and prove them.

\section{Example 1: Short cut}

a) Develop a short method to calculate

$$
17+16+15+14+\ldots+3+2+1 .
$$

b) Use your method to calculate

$$
1+2+3+4+5+\ldots+99+100 \text {. }
$$

c) Generalise!

d) Can you use your method to calculate

$$
2+4+6+8+10+\ldots+98+100 ?
$$

e) Can you use your method to calculate

$$
1+3+5+7+9+\ldots+97+99 ?
$$

\section{Example 2: Consecutive numbers}

Some numbers can be written as the sum of two or more consecutive whole numbers.

For example: $13=6+7$

$$
\begin{aligned}
& 14=2+3+4+5 \\
& 15=7+8=1+2+3+4+5
\end{aligned}
$$

Some numbers cannot be written as the sum of consecutive whole numbers.

Investigate: Which numbers can and which numbers cannot be written as the sum of consecutive whole numbers. Try to develop a general theory or method or formula that will enable you to:

a) Immediately decide if any given number can be written as the sum of consecutive numbers.

b) Easily write the number as the sum of consecutive numbers.

a) Find the value of

\section{Example 3: Generalise}

$$
\left(1-\frac{1}{4}\right)\left(1-\frac{1}{9}\right)\left(1-\frac{1}{16}\right)\left(1-\frac{1}{25}\right)\left(1-\frac{1}{36}\right) \ldots\left(1-\frac{1}{10000}\right)
$$

b) Generalise.

\section{Example 4: Petrol price}

In January the petrol price is increased by $10 \%$. Then, in February the petrol price was reduced by $10 \%$. John says that the petrol price is now the same as it was before the first increase. Is this correct? Explain!

\section{Impact of the course on teachers}

In 2002, twenty-seven teachers of grades 10 to 12 mathematics enrolled for the Mathematics for Teachers course. The majority of the teachers were 
teaching at rural black schools. The reflective journals provided us with documentation of a continuous cycle of inquiry. Apart from the journal, various data were gathered in order to assess the impact of the course. At both the beginning and the end of the course the teachers completed a questionnaire and a test. The questionnaire asked teachers to indicate their level of confidence about teaching various topics in the grades 10,11 and 12 syllabi using a 5-point Likert scale. The test comprised questions similar to those on the grade 12 examinations and included questions with a range of levels of cognitive demand (see Appendix A). The same questionnaire and test were administered at both the beginning and the end of the course. Further information was obtained from teachers' assignments, journals, evaluations completed at the end of workshops and an end-of-year evaluation.

\section{Effects on teachers' content knowledge}

At the end of the course we asked the teachers to evaluate the course by completing a questionnaire. We divided the free response questions into categories. Thirteen teachers completed and returned the questionnaire/survey. The respondents gave feedback on the impact of the course on their content knowledge and teaching practice as follows:

1) Has the course improved your subject content knowledge?

- Yes: $13(100 \%)$.

- No: 0.

2) In what ways has the course improved your subject content knowledge?

- Improved problem-solving skills: 6 (46\%).

- Improved mathematical thinking skills: 3 $(23 \%)$.

- No response: 4 (31\%).

3) In what ways has the course failed to improve your content knowledge?

- None: 11 (85\%).

4) Has the course improved your teaching practice?

- Yes: 13 (100\%).

- No: 0.

5) In what ways has the course improved your teaching practice?

- More confidence: 1 (8\%).

- Learners are more interested: $1(8 \%)$.

- Improved learners' class attendance: 1 (8\%).

- Improved teachers' problem-solving skills: 3 $(23 \%)$.

- Improved teaching skills: 3 (23\%).

The pre- and post-tests showed that there was a
$13.6 \%$ improvement in the teachers' ability to answer grade 12 exam-type Higher Grade questions (see Figure 1). The average mark was $32.4 \%$ for the pre-test and $46 \%$ for the post-test.

The improvement in the teachers' ability to answer grade 12 exam-type Higher Grade questions was unexpected, because the course did not explicitly focus on the content knowledge that was tested in the pre- and post-test.

Some of the comments that the teachers made in the journals were:

I am discovering something new every day in my learning. My knowledge horizon is expanding although I have been a teacher for more that 15 years.

I have discovered ways of attempting a problem if you don't have a clue of what to do. It has helped me to upgrade my mathematical insight.

\section{Effects on classroom practice}

Anecdotally, the course had an impact on the classroom practice of the teachers. Some of the comments they made were:

The weeks' work will affect my classroom practice in that I will simply be moving away from the traditional way of teaching. I will make sure that the learners learn through social interaction and reflection, no longer through practice and repetition. I will present tasks and problems that will lead the learners to inventing mathematics.

This piece of work will enrich the knowledge of my learners as far as arithmetic sequence is concerned. This is very exciting, as they will have a deeper understanding of the concept.

The learners are more interested in mathematics, understand it more quickly and attend their classes better.

All of these exercises empower you to teach certain topics... it is true that experience is the best teacher.

\section{Effects on teachers' attitudes towards mathematics}

From the feedback it was evident that all the respondents believed that the course had improved their teaching practice. According to them they are more confident than before about teaching mathematics. One of the teachers wrote:

One is empowered to teach in the classroom without fear. The students 
understand me more clearly than before I registered for this course.

The course also changed the way that some of the teachers think about mathematics:

It was very challenging and has changed my mindset about mathematics so that I now realise that mathematics is about discovery and about being able to make con-

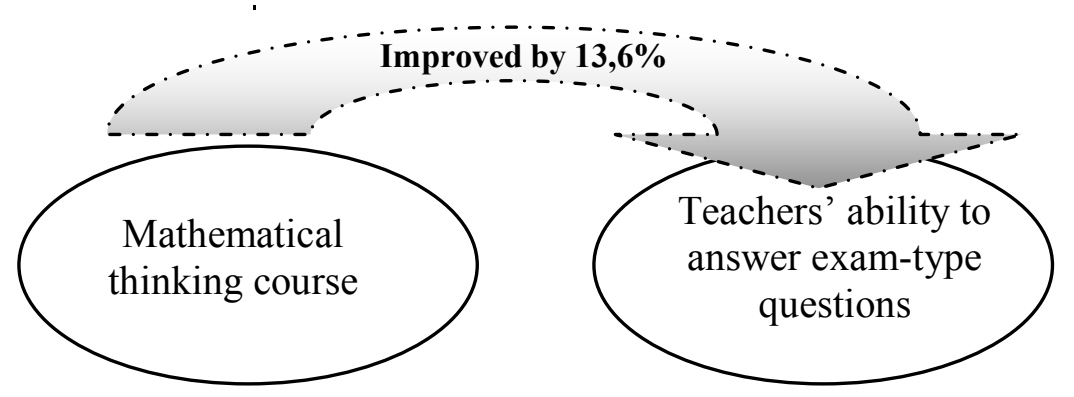

Figure 1. Improvement in the teachers' ability to answer exam-type questions jectures and to reason.

\section{Effects on teachers' reflective skills}

Initially the teachers were very negative about the weekly journal entries, but their attitude changed as they progressed. In the beginning one of the teachers wrote: "I think that the journal exhausts our study time". Later in the year, the same teacher wrote:

I am now developing a positive attitude about this journal. I can see that the questions in the journals help us to link what we have learnt in the study guide with the activities in the classroom situation.

Twenty of the 27 teachers were from the same geographical area, which contributed to the fact that $77 \%$ of the teachers worked with peers. The journals and the fact of working with peers helped the teachers to be more reflective. The journal gave the researchers some insight into what was going on in the teachers' minds during the problemsolving course. In the beginning of the course the teachers expressed their frustrations:

This was too demanding and thought provoking. One had to recognise patterns which were not always easy to find.

The assignment is really challenging. I didn't expect this. I am thinking of stopping this course.

As I am working through this unit, I am getting frustrated ... I see the problems for the first time.

Some of the teachers complained about the study guide. They wanted examples, followed by similar problems to solve. They looked for examples in other books:

As I was working through this unit, I was frustrated. I was frustrated to see myself reading so many books and not finding the exact book that would provide me with relevant information.

But the frustration soon changed into joy. The same teacher wrote some time later:

My frustration ended in excitement. Even

though I was frustrated, at the end of

each and every question I had gained something exciting.

One teacher wrote in her journal: "I am really frustrated. I wish I could get the answer." Two days later she wrote:

At last I got the answer and I am so happy. No amount of money can buy my happiness.

\section{Possible impact of the course on the learners}

The study only determined the impact of the course on the teachers. Although we attended some of the teachers' classes, we could not determine the impact of the course on their classroom practice. Instead of trying to determine the direct impact of the course on the learners, we decided to divide the investigation into two parts. The first question we asked was: is there a correlation between the teachers' knowledge and their learners' knowledge? The second question was whether this course improved the teachers' knowledge.

What we know is that there is a strong correlation between the teachers' knowledge and their learners' knowledge. A previous study undertaken by Stols (2003: 246-250) with the same teachers revealed that the correlation between these teachers' ability to answer exam-type questions and the learners' ability to answer similar examtype questions is very strong (the Pearson correlation coefficient is 0.8008 ; this correlation is statistically significant, because of the low P-value of 0.0005).

Therefore, improving the teachers' ability to answer exam-type questions will also improve their learners' ability (see Figure 2). In the results, we mentioned that the teachers' ability to answer 


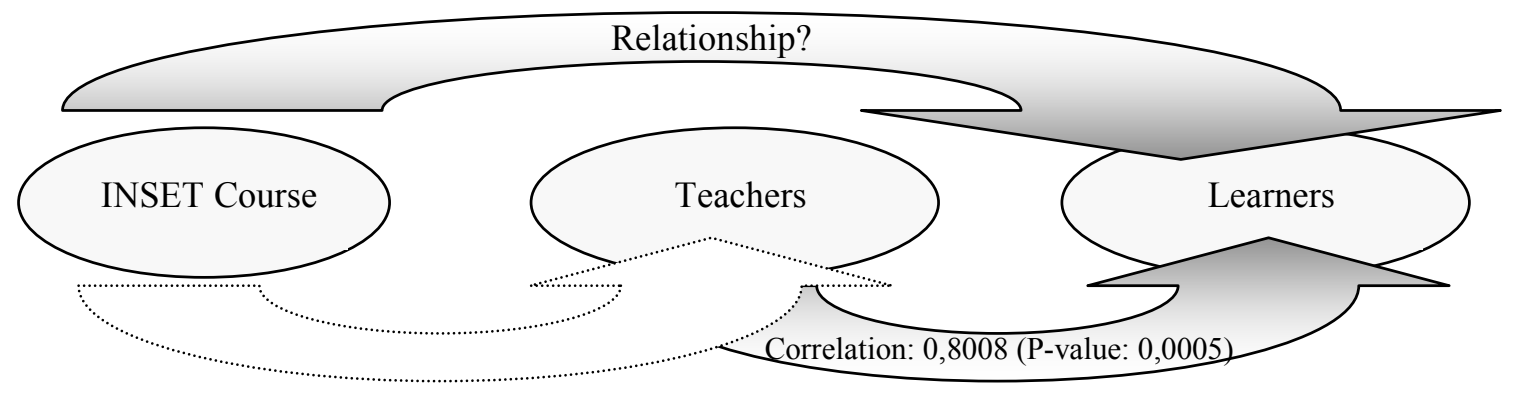

Figure 2. The relationship between teachers' and learners' abilities

exam-type questions improved by $13,6 \%$. It is therefore reasonable to believe that this problemsolving course in mathematical thinking could help the learners as well. This belief was confirmed by the results for one school. The pass rate of the grade 12 learners in Mathematics Higher Grade in this school was $51.4 \%$ in 2001 and it improved to $94.4 \%$ in 2002 (that is the year in which the mathematics teacher at the school was enrolled for this course). The teacher believes that the improvement in the results was due his participation in this course.

\section{Discussion}

The course improved the confidence, problemsolving skills and teaching skills of the teachers. One of the teachers who did the course wrote in his journal:

I believe that creativity is there in each and every mind. It only needs to be activated in order to make it useful in other situations.

The course also improved the teachers' content knowledge because it helped them to help themselves to master content. It is clear from the comments by the teachers that this course (problem-solving approach) helped the teachers to improve their metacognitive skills. A possible reason is that teachers have become more reflective because of the journals they kept and another possible reason is that a problem-solving approach may help teachers to enhance their metacognitive skills. Routine exercises on the other hand may engender a false impression of success and understanding because it is possible to experience success without understanding.

We would conclude that teacher training programmes that are organised around problemsolving and that are directly related to teachers' work with their students are a powerful means of helping teachers who are preparing to teach mathematics. This approach will help teachers to become more reflective and will develop their metacognitive skills. It will help them to help themselves in future.

\section{Conclusion}

To prepare teachers to help learners learn mathematics is not easy. Traditionally, the focus of teacher training programmes was on the upgrading of content knowledge and on ways of explaining the new knowledge to learners. But Schoenfeld (1994) states that teachers need more than that: "The danger in this kind of 'content inventory' point of view comes from what it leaves out: The critically important point is that mathematical thinking consists of a lot more than knowing facts, theorems, techniques, etc." It remains important, however, that the teachers should at least know the mathematics they teach. Yet, considering the requirements outlined above, it is clear that they must know more than that. Ball (2003) explains the knowledge that teachers need as follows:

Teaching requires justifying, explaining, analysing errors, generalising, and defining. It requires knowing ideas and procedures in detail, and knowing them well enough to represent and explain them skilfully in more than one way. This is mathematics. The failure to appreciate that this is substantial mathematical work does teachers - and the improvement of teaching - a disservice. (2003: 4)

This course helps teachers deepen their content knowledge and their pedagogical content knowledge, improve their problem-solving skills, and develop their metacognitive skills so that they can continue to learn in future without relying on a structured course. Because of the strong correlation between teachers' knowledge and learners' knowledge, the course will eventually make a difference in the classroom. 


\section{Acknowledgements}

This paper was made possible by a grant from the Carnegie Corporation of New York. The statements made and views expressed are solely those of the author.

\section{References}

Ball, D.L. (2003). Mathematics in the 21st Century: What mathematical knowledge is needed for teaching mathematics? Retrieved November 28, 2003, from http://www.ed.gov/ inits/mathscience/ball.html

Confrey, J. \& Lachance, A. (2000). Transformative teaching experiments through conjecture-driven research design. In A.E. Kelly. (Ed.), Handbook of research design in mathematics and science education (pp. 231-266). New Jersey: Lawrence Erlbaum Associates.

Department of Education. (2001). National strategy for mathematics, science and technology education to address the problem in mathematics, science and technology education. Pretoria: Department of Education.

Department of Education. (2003). National Curriculum Statements Grades 10-12 (General): Mathematics. Pretoria: Department of Education.

Dossey, J., McCrone, S., Giordano, F. \& Weir, M.D. (2002). Mathematics methods and modelling for today's mathematics classroom: a contemporary approach to teaching grades 712. Canada: Brooks \& Cole.

Education Development Centre (2000). Connected geometry: Teachers guide. Chicago: Everyday Learning.

Kahn, M. (2004). For whom the second bell tolls: Disparities in performance in Senior Certificate Mathematics and Physical Science. Perspectives in Education, 30(4), 149-156.

Loucks-Horsely, S., Hewson, P., Love, N. \& Stiles, K. (1998). Designing professional development for teachers of science and mathematics. Thousand Oaks, CA: Corwin Press.

National Commission on Teaching and America's Future (1996). What Matters Most: Teaching For America's Future. Summary Report. New York: National Commission on Teaching and America's Future.

Olivier, A. (2000). Study Guide: Mathematics for Teachers I. Pretoria: UNISA Publishers.

Resnick, L. (1989). Treating mathematics as an illstructured discipline. In R. Charles \& E. Silver (Eds.), The teaching and assessing of mathematical problem-solving (pp. 32-60). Reston, VA: National Council of teachers of Mathematics.

Schoenfeld, A.H. (1994). What do we know about mathematics curricula? Journal of Mathematics Behaviour, 13, 55-80.

Stols, G.H. (2003). The correlation between teachers' and their learners' mathematical knowledge in rural schools. In P. Bongile, M. Dlamini, B. Dlamini, \& V. Kelly. (Eds.), Proceedings of the $11^{\text {th }}$ Annual SAARMSTE Conference (pp. 246-250). Cape Town: University of Cape Town.

Taylor, N. \& Vinjevold, P. (1999). Getting Learning Right. Johannesburg: Joint Education Trust.

\section{Appendix A: Pre- and post-test}

Please answer the following questions without obtaining help from anyone.

1. Solve for $x: \frac{6}{x-1} \leq x ; x \neq 1$

2. For which values of $\mathrm{k}$ are the roots of $\frac{x+2}{x^{2}+2 x+1}=\mathrm{k}$ with $x \neq-1$ real?

3. Solve for $x$ : $9^{x}+3^{x}=27\left(3^{x}+1\right)$

4. A house contractor has subdivided a farm into 100 building lots. He has designed two types of homes for these lots: colonial and ranch style. A colonial home requires R300 000 of capital and yields a profit of R40 000 when sold. A ranch-style house requires R400 000 of capital and yields an R80 000 profit. If he has R36 million of capital on hand, how many of each type should he build for maximum profit? Will any of the lots be vacant?

5. If $a x^{2}+b x+c=0$ and $a+b+c=0$ find the numerical value of $x$.

6. Show that $\mathrm{a}=0$ if $x=\frac{2 \mathrm{a}+2 \mathrm{ba}^{2} x-\mathrm{a}-2 \mathrm{bax}}{2 \mathrm{a}^{2} \mathrm{~b}-2 \mathrm{ba}}$

7. Solve for $x$ and $y:\left(x^{2}-4\right)\left(y-\frac{1}{y}\right)=0$

8. Is the following statement true: $\left(a^{\frac{1}{2}}+a^{-\frac{1}{2}}\right)^{2}=a+a^{-1}$ ? Why?

9. Is the following statement true: $2\left(4^{x}+4^{-x}\right)=8^{x}+8^{-x}$ ? Why?

10. Solve for $x:\left(x^{2}+2 x\right)^{2}-x^{2}-2 x-6=0$ 